\title{
Adolescents' Limited Eclectic Personal Ethics and Heuristic Ways of Resolving Moral Problems ${ }^{1}$
}

\section{Eric Datu Agustin}

Dr., Alumnus, University of the Philippines, Philippines, edagustin@alum.up.edu.ph

Ethical theories are key principles that determine right decisions and actions in morally problematic situations. Using phenomenological method of data collection, explication, and interpretative, the adolescent interviewees in this study revealed the essential nature, structure, content, and meaning of their personal moral beliefs and other determinants in resolving moral problems. The phenomenological analysis of data uncovered six (6) themes: (1) tapping traits characteristically; (2) experiencing the morality of a problem; (3) influencing factors from the local contexts, (4) wielding to one's advantage personal moral beliefs (PMBs), (5) externalizing moral reflectiveness when utilizing PMBs, and, (6) disclosing moral consistency in applying PMBs. The phenomenological theme indicated that youth participants' personal moral convictions and related factors guided them to resolve reflectively, consistently and heuristically their ethical problems. The overall finding implies the need to focus more on individual adolescents' limited eclectic personal ethics and associated life aspects for the development of holistic societal members.

Keywords: eclectic personal ethics, moral problem, limited moral experience, personal characteristics, heuristic ways

\section{INTRODUCTION}

Ethical philosophies are topics of enduring interest in education (Fleming, 2004). They are used when resolving moral problems to develop holistic individuals (UNESCO, 2002). In addition, philosophy of ethics deals, not just with virtues, but also with other moral concerns (e.g., autonomy, care, confidentiality, consequences, divine will, fairness, fidelity, goodwill, growth, justice, lawfulness, obligation, nonmaleficence,

\footnotetext{
${ }^{1}$ This article is written from PhD Dissertation, Students' Personal Moral Beliefs and Ways of Resolving Moral Problems, accepted by University of the Philippines, College of Education in Quezon City.

Citation: Agustin, E. D. (2019). Adolescents' Limited Eclectic Personal Ethics and Heuristic Ways of Resolving Moral Problems. International Journal of Instruction, 12(1), 1351-1366. https://doi.org/10.29333/iji.2019.12186a
} 
principles of human worth, respect, rights, social contract, success, veracity, inter alia). Despite a growing number of studies about ethical philosophies (Riley, 2013; Stichter, 2018), the Philippine Department of Education (DepEd) continues to rely on virtue ethics theory as its framework for Values/Moral Education (Philippine Department of Education, 2012; SEAMEO-INNOTECH, 2012). Adopting a millennia-old western virtue ethics might be a good idea, but it also attracts persistent doubts and concerns.

In the seminal papers of various ethicists, arguably, Virtue Ethics alone could not accommodate moral problems because one man's happiness is relative from another individual to the other (Foot, 1983; Fried, 1997; Schroeder, 2008). Likewise, no single ethical principle is clearly better than other theories or seems to work for everybody because there is no consensus on their ranking (Fried, 1997). Moreover, a person who falls short in one virtue (e.g., for having chosen one among alternative virtues under dilemmatic situations), may also fall short in other virtues (McAleer, 2006). Plausibly, being a virtuous individual is more than just having one virtue. Aside from the fact that most, if not all, ethical philosophies have subtle and not-so subtle complexities and weaknesses, using Virtue Ethics alone as a framework (i.e., to the exclusion of other ethical philosophies), implies DepEd's disregard, of adolescent students' personal or commonsense ethical philosophies, which are derived from youth's personal characteristics, daily experiences, and moral contexts.

A person's identity has complex and multifaceted dimensions (e.g., material, teleological, metaphysical) (Camp, 2016). No one, or even several ethical philosophies, could possibly define what a single person is in his or her totality (e.g., personal moral identity, artistry, ingenuity, among others). Even with the advent of personalism, existentialism, humanism, phenomenology, and so on, a singular encapsulated conception of an individual seems not enough (Becker \& Becker, 2013; Shoemaker, 2015). Even with advances in knowledge, a person is still in constant pursuit of his or her essences. Although an individual's knowledge and understanding has open up meaningful discoveries and breakthroughs for himself or herself and other people, he or she remains an unfathomable being in search for a better self and worthwhile existence (Rocca, 2014).

Considering that each person has distinct personal moral identity and moral experiences, knowing how and why a person derives or emerges out of himself or herself, as well as, in his or her everyday interactions using various personal ethical beliefs when confronted with different moral problems is, indeed, significant (Niemirowski, 2014). It seems that a person influences himself or herself (i.e., intrapersonally) as he or she interacts interpersonally with other people and surrounding, and vice versa. Out of a person's identity, personal experiences, and moral contexts come forth his or her subjectivity to be reflective both with his or her interior and exterior worlds. Thus, in the context of educational philosophy, an individual is what he or she makes out of himself or herself. He or she is born to be self-conscious of his or her actual existence using his or her affect, intellect, freewill, and other natural endowments and entitlements, with the awareness to "moral issues that in everyday life are more often expressed by ordinary people via religious, social, and somatic idioms" (Kleinman, 1999, p. 69). 
In the world where a person lives in, he or she thus keeps on searching for a meaningful existence while he or she continuously enriches his or her "interiority" proportionate with the depth of his or her personal characteristics, learning experiences, and personal [moral] growth (Magsino, 2013, p. 172). Hence, given the human person's complexity, this study has thus attempted to discover how and why an adolescent student uses his or her own ordinary personal moral belief system when resolving moral problems, which are parts of his or her "life with others" (Das, 2012, p. 133). Specifically, this study examined why and how youth's self-identity, everyday experiences, and moral context influence his or her ethical judgment of "local knowledge" (e.g., values, virtues, and other essences) that shaped the content and form of his or her ethical precepts (Christakis, 1992). Despite what has already been stated above, this study did not lean on any one ethical philosophy, but only analyzed and interpreted adolescent students' personal ethical perspectives vis-à-vis previous research findings. It thus explored "the moral work of people [specifically, students] engaged in trying to create good lives for themselves and those they care about" (Mattingly, 2012, p. 301).

So far, a large gap exists in research because only a few studies specifically focused on learners' personal moral beliefs, self-identity, moral experiences, and local contexts as used in resolving various moral problems. Previous local studies, for instance, concerned themselves mostly on philosophical skills of pre-service education students (Acido, 2004), students' values as influenced by familial, academic and social values (De Leon, 1995), integral education and a particular realist personalist philosophy (Magsino, 2013), and secondary school teachers' ethical framework (Santiago, 2012). Likewise, some foreign researchers dealt primarily with Vygotsky's Collaborative Approach in teaching moral education using real-life moral dilemmas (Balakrishnan, 2009), studied moral realism and moral dilemmas (Foot, 1983), revealed the association between students' critical thinking and community of inquiry approach (Freakley \& Burgh, 1998), among others. This study, on the other hand, shares its interesting objectives of arriving at worthwhile research findings about students' personal moral beliefs and related life aspects used in resolving a variety of moral problems, as an alternative pedagogical approach in teaching the subject Values/Moral Education, Philosophy of the Human Person or Ethics.

\section{Significance of the Study}

As a response to the personalism and virtue philosophy mandated by DepEd, this study utilized phenomenological analysis of adolescent students' personal philosophies that were used to resolve true-to-life moral problems and which led to the emergence of new knowledge and insight into the field of educational philosophy. Just as many individuals resort to their personal moral belief systems, judgments, or convictions to resolve ethical conflicts, so, did the students. Since personal philosophies, ethical judgment, and moral resolutions to moral problems are unavoidable, this study has been significant in better informing educational theory and practice. Additionally, this research has offered some beneficial ideas, insights, and improvement, and where a personalized eclectic teachinglearning approach to Values or Moral Education is one of the most qualified candidates in the development of holistic learners. 
Considering that so much emphasis is given on an individual's autonomy, dignity, freedom, rationality, rights, and so forth, studying people's own conception of their values, judiciousness or injudiciousness of their decisions and actions, inter alia, from an ethical-phenomenological approach, offered a better understanding of the human person's moral self-identity; that is, given the understanding that

"no philosophical interpretation of the structure of moral experience - not even a systematic moral theory - can solve [all] moral problems; [nonetheless,] it can influence the decisions and actions of human beings who contemplate the implications, principally by virtue of its tendency to encourage self-scrutiny" (Moody-Adams, 1997, p. 170).

Hence, this study provided a meaningful understanding of each learner's personal moral learning process. Likewise, this study has produced a phenomenological theme about the personal moral beliefs of adolescent students and their responses to moral problems using their personal characteristics, lived experiences, local contexts, and other factors.

\section{METHOD}

Phenomenological research design was used in explicating and interpreting the respondents' use of their personal moral beliefs as guides in resolving morally problematic situations in the context of their lives. In researching on young students' multi-layered moral lifeworld, rich and deep reflective narratives and not the testing of a pre-determined set of hypotheses was obtained from them. As such, the findings of the phenomenological approach on adolescent students' lived experiences were within the context of educational philosophical research and literature used in this study's analysis and interpretation in view of previous findings.

The phenomenological approach investigated the phenomenon, described the themes obtained from and within each student's interview feedbacks, examined the relationship between themes, and then interpreted patterns as the phenomenological theme emerged from the overall findings. The approach revealed how each adolescent's response was unique given the ultimate essence of the experiences. A variety of multiple perspectives to view the lived moral worlds of the adolescent students was highlighted, hence, making the personal, "not necessarily private" (Küpers, 2009, p. 71). Further, phenomenology was used in investigating the phenomenon (i.e., "a thing that show itself") by returning to the "things themselves" through phenomenological reduction of presuppositions, examination of the relationship of the essences (core meaning) of a person's experience, and exploration of the inseparable connectedness of meanings, and interpretation of an individual's lifeworld with other peoples' life worlds (Heidegger, Macquarrie, \& Robinson, 2005; Husserl, 1900/1970; Merleau-Ponty, 1945/2013).

Adolescents' descriptions of their personal beliefs was depicted as a structure of underlying and precipitating factors for what they have experienced so far in life (Merriam, 2007). As a systematic approach, a paradigm based on the data was used. From the interview method used and data gathered, key points as notes, codes, and concepts were marked and then grouped into workable categories, patterns, and themes. 


\section{Study Participants}

Purposeful research sampling was a key decision point in maximizing the utility of specific information obtained from the small sample size which, according to Englander (2012), "[was] irrelevant due to the fact that [this] research [was] qualitative and not quantitative" (p. 20). Maximum variation sampling (quota selection) illuminated the various facets of the research problems that obtained the broadest range of young students' views and information.

Since validity has not been an issue in this phenomenological study, but relevance, workability, modifiability, and fit, twelve (12) adolescents participated voluntarily for the one-on-one in-depth interview research proper (Smith \& Osborn, 2015). Hence, the validity of the research findings, which was the accurate representation of the phenomenon from the recommended number of two to 10 participants in a phenomenological research, was ensured (Creswell \& Poth, 2018; Englander, 2012).

The interviewees were graduating secondary school students from a public high school. They were chosen as interviewees because of their homogeneity (e.g., cream of the crop, non-sectarian institution), school's philosophy of developing holistic individuals, and school's non-religious affiliations. The names of each interviewee were changed into numbers to safeguard confidentiality.

\section{The Research Instrument}

The research instrument was an in-depth, open-ended interview questionnaire that allowed for a holistic understanding of the participant's feedback for further investigation. It triggered a rediscovering of the self through a dialogic and reflective questioning and answering at a conscious level. As an expertly validated instrument, it was constructed to get in-depth interviewees' feedbacks about subjective elements of expression, reflection, analyses, and evaluation of lived moral experiences in various educative processes and contexts. Since phenomenological research puts an emphasis on effective research questioning concerning personal and social meanings, the interview questions focused on individual respondents' moral problem resolution with respect to their moral convictions and related factors (Moustakas, 1994; van Manen, 1990).

\section{Data Explication and Interpretation Technique}

In the explication and interpretation of the interview transcripts using the phenomenological process, evidences were accurate and replicable digital recordings of the subsequently transcribed, reread, open coded, clustered and categorized, and thematized interviewees' responses as to how the participants made meanings of their lived moral worlds. Accuracy criteria for data explication included trustworthiness (reliability), conformability (objectivity), credibility (internal validity), and transferability (external validity). Contents of the interviews, codes, categories, themes, and patterns were given to two faculty members, which provided their expert opinions on qualitative researches.

Subsequently, narratives and themes were presented that reliably represented the interviewees' own voice. Giorgi's (1988) data analytic method was used in this study 
where member checking or validation of the findings by the participants (or even by external judges) was no longer necessary or was "inappropriate since [the participants] had described their experiences from an everyday perspective" (p. 137) despite systematically documenting the research process for transparency purposes. Hence, given that there is no definitive answer to validity and reliability issues, to reduce element or lone researcher bias and make data analysis more rigorous, data explication was done as systematic, rigorous and thorough as possible (i.e., including not only significant findings but also outliers, deviant or contrary cases in providing meaning and significance to the phenomenon of interest) (Hong, Guo, \& Chen, 2015). Likewise, a qualitative researcher (who served as peer critic, peer debriefer, or peer reviewer) analyzed independently the data and thus even offered additional insights into further theme and theory development.

\section{FINDINGS}

This section provides the research findings from high school adolescent interviewees' personal moral beliefs (PMBs) as guides in the resolution of their moral problems (MPs). Likewise, participants' personal characteristics (PCs), moral experiences (MEs), and factors from the local context (FLCs) were also examined concerning their contribution in the generation of the overarching, subordinate, and phenomenological themes. Table 1 shows the said themes that emerged from the analysis of the data from the 12 participants: 
Table 1

List of overarching themes and subordinate themes

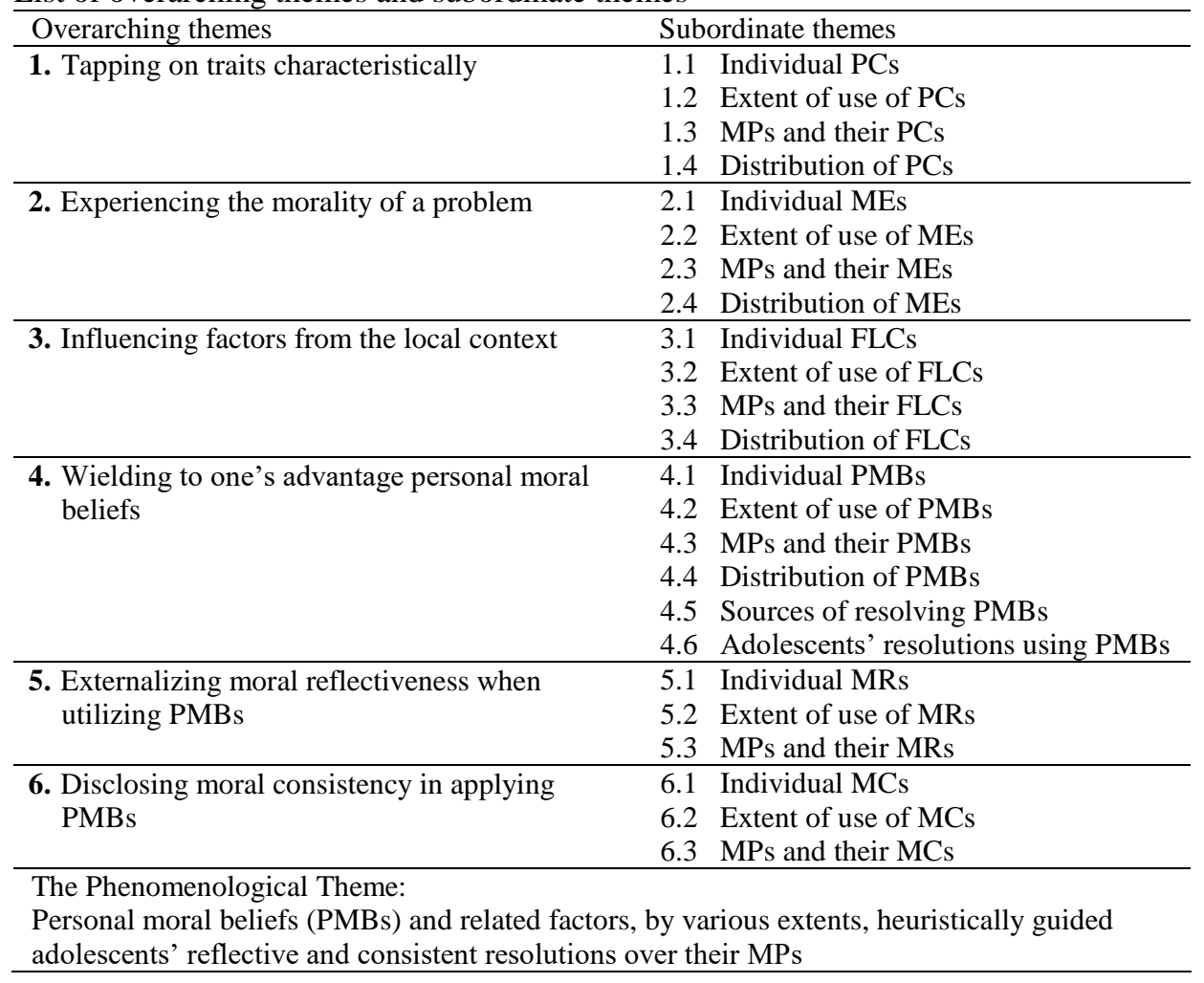

The essential themes and sub-themes were derived from the interviewees' narrative accounts as they decided over their MPs using various factors or influencers (e.g., PCs, MEs, FLCs, and PMBs). The interviewees' own voices and perspectives helped in illuminating, explaining, understanding, and finding a common pattern of personal attributes, moral experiences, environmental influence, and moral conviction when deciding over MPs. Nevertheless, this study was not specifically for generalization outside of the context of this research in arriving at a phenomenological theme.

In the presentation, explication, and interpretation of the answers to the research questions, interview extracts, and illustrations, respective themes and their sub-theme were used to discuss significant key cases and outlying representative samples. For example, under Themes 1 to 6 and their sub-themes 1.1, 2.1, 3.1, 4.1, 5.1, and 6.1, two representative samples were used: Participant 1 who resolved three $(100 \%)$ MPs and Participant 7 who did not resolve any (0\%) MPs; that is, using their respective PCs, FLCs, MEs, and PMBs. In other words, Participant 1 (a key case) and Participant 7 (an outlier) were used as representatives in resolving or not resolving their MPs using 
phenomenological data analysis or the processes of coding, categorizing, and making sense of qualitative data.

In addition to Themes 1 to 6 and their sub-themes: $1.2,2.2,3.2,4.2,5.2$, and 6.2; 1.3, 2.3, 3.3, 4.3, 5.3, and 6.3; and, 1.4, 2.4, 3.4, and 4.4, Participants 3 and 6, 10 and 11, 8, 5,4 and 9 , as well as, 2 and 12 were also used as representative subjects under the different extent to which they used similar or different PCs, FLCs, MEs, and PMBs to reflectively and consistently resolve or not their similar or different MPs. Further, additional sub-themes that emerged aided in the analysis and interpretation of the results. Overall, all participants were included in the exhaustive discussions of the findings in the emergence of the phenomenological theme for a holistic understanding of the local moral worlds of the students. In Table 2, here is what it looks like:

Table 2

Overview of essential themes and sub-themes

\begin{tabular}{|c|c|c|c|c|c|c|}
\hline $\begin{array}{l}\text { Participant } \\
\text { no. }\end{array}$ & $\begin{array}{l}\text { Total MPs }{ }^{2} \\
\text { resolved } \\
\left(\mathrm{TMR}^{3}\right)\end{array}$ & Sample MP used ${ }^{4}$ & Theme & Sub-theme & $\begin{array}{l}\text { Categorization / } \\
\text { Classification }\end{array}$ & $\begin{array}{l}\text { 4-Factor / } \\
\text { Heuristic } \\
\text { Resolution, } \\
\text { Reflectiveness; } \\
\text { Consistency }\end{array}$ \\
\hline 1 & $100 \%$ & Rullving & \multirow{13}{*}{$\begin{array}{l}\text { 1) } \mathrm{PC} \\
\text { 2) } \mathrm{FLC} \\
\text { 3) } \mathrm{ME} \\
\text { 4) } \mathrm{PMB} \\
\text { 5) } \mathrm{MR} \\
\text { 6) } \mathrm{MC}\end{array}$} & \multirow{2}{*}{$\begin{array}{l}\text { By individual } \\
\text { participants }\end{array}$} & Key case & $\mathrm{R}, \mathrm{Re}, \mathrm{C}$ \\
\hline 7 & $0 \%$ & Duinymg & & & Outlier & $\mathrm{N}, \mathrm{Re}, \mathrm{C}$ \\
\hline 3 & $33 \%$ & \multirow{2}{*}{ Church-going } & & \multirow{8}{*}{$\begin{array}{l}\text { By extent of } \\
\text { resolution }\end{array}$} & \multirow{2}{*}{$\mathrm{a}, \mathrm{c}, \mathrm{e}$} & $\mathrm{R}, \mathrm{Re}, \mathrm{C}$ \\
\hline 6 & $67 \%$ & & & & & $\mathrm{R}, \mathrm{Re}, \mathrm{C}$ \\
\hline 10 & $100 \%$ & Bullying & & & \multirow[b]{2}{*}{$\mathrm{b}, \mathrm{e}$} & $\mathrm{R}, \mathrm{Re}, \mathrm{C}$ \\
\hline 11 & $67 \%$ & $\begin{array}{l}\text { Filial } \\
\text { sassing }\end{array}$ & & & & $\mathrm{R}, \mathrm{Re}, \mathrm{C}$ \\
\hline 8 & $100 \%$ & Familial lyings & & & $\mathrm{c}$ & $\begin{array}{l}\text { T, Re, C } \\
\text { T, NeR, NeC }\end{array}$ \\
\hline 5 & $84 \%$ & Shyness & & & $\mathrm{f}$ & $\mathrm{Ne}, \mathrm{Re}, \mathrm{NC}$ \\
\hline 4 & $33 \%$ & Academic cheating & & & \multirow[b]{2}{*}{$\mathrm{d}, \mathrm{e}$} & $\mathrm{N}, \mathrm{NeR}, \mathrm{NeC}$ \\
\hline 9 & $67 \%$ & Bullying & & & & $\mathrm{N}, \mathrm{Re}, \mathrm{C}$ \\
\hline 2 & $67 \%$ & Physical defect & & \multirow{2}{*}{$\begin{array}{l}\text { By particular } \\
\text { moral problems }\end{array}$} & \multirow{2}{*}{ c. $2, \mathrm{~d} .2$} & $\mathrm{~N}, \mathrm{Re}, \mathrm{C}$ \\
\hline 12 & $33 \%$ & Academic cheating & & & & $\mathrm{N}, \mathrm{No}, \mathrm{NC}$ \\
\hline $1-12$ & $100 \%-0 \%$ & All MPs & & By distribution & Not applicable & $\begin{array}{l}\text { Not } \\
\text { applicable }\end{array}$ \\
\hline
\end{tabular}

Legend 1: $\mathrm{PC}=$ personal characteristics; $\mathrm{FLC}=$ factors from the local context; $\mathrm{ME}=$ moral experience; $\mathrm{PMB}=$ personal moral belief; $\mathrm{MR}=$ moral reflectiveness; $\mathrm{MC}=$ moral consistency.

${ }^{2}$ Each participant has shared three (3) MPs or the 12 participants mentioned a total of 36 MPs.

${ }^{3}$ The "Total MPs resolved (TMR)" column refers to the percentage of resolved MPs over total MPs by each participant.

${ }^{4}$ The "Sample MP used" column refers to the significant representative qualitative MPs used for the various presentations, analyses, and interpretations under all themes and sub-themes.

5 "Categorization / Classification" of samples was for comparison (similarities) and contrast (differences) of the participants' use of PCs, FLCs, MEs, and PMBs (that is, a to f) as they decided over their MPs (e.g., Participant 1 was a key case and Participant 7 was an outlier case) 
Legend 2: $\mathrm{R}=$ resolved; $\mathrm{T}=$ temporarily resolved; $\mathrm{Re}=$ reflective, $\mathrm{NeR}=$ neutrally/ambivalently reflective; NRef $=$ nonreflective; Con $=$ consistent; NeRef $=$ neutrally/ambivalently reflective.; NCon $=$ not consistent or inconsistent

Overall, all participants were included, such that their interview responses were contextually and thematically discussed, analyzed, synthesized and interpreted to understand ways of resolving MPs to arrive at the phenomenological theme that PMBs and related factors guided the resolution of MPs. Hence, for a complete understanding of the use of Table 2, research questions and their answers were succinctly presented in the Discussions section, hereunder:

\section{DISCUSSION}

This section discusses the summary of findings, conclusion, and recommendations concerning participants' personal characteristics, moral experiences, and factors from the local context that contributed in the development of the phenomenological theme on lived limited eclectic personal moral beliefs and related factors for moral problem resolutions.

Research Problem 1: What personal characteristics (PCs) influenced adolescents' ways of resolving their moral problems (MPs)?

A variety of PCs (e.g., humility, discipline, conscientiousness) influenced in various ways the resolution of participants' MPs (e.g., arrogance, familial lying, academic cheating). Moreover, PCs, whether similar or dissimilar, impacted on MP resolution. Further, PCs mentioned under particular MPs reemerged within and across MPs and their themes. Concisely, Theme 1 and its sub-themes revealed that adolescents' PCs influenced in various ways the resolution of majority of MPs, and the inverse was more likely untrue (Wagner \& Ruch, 2015; Zhang \& Chen, 2018).

Research Problem 2: What moral experiences (MEs) affected adolescents' manner of resolving their moral problems (MPs)?

Individual MEs (e.g., admonishment, religious experience, acceptance) affected the resolution of participants' MPs (e.g., arrogance, familial lying, physical defect). In other words, adolescents' everyday MEs and conduct, moral upbringing or education at home, not to mention social solidarity were, indeed, found to be as important for moral growth and development (Iwasa, 2017). Moreover, MEs that aided in the resolution of MPs, despite similarities or dissimilarities from one another, mostly resolved adolescent students' MPs. Interestingly also, MEs mentioned under particular MPs reemerged within and across MPs and their themes. Nonetheless, the moral experiences confided by the research participants were indeed experiences qualified and demarcated yet systemized in various moral terms (Zigon \& Throop, 2014). Laconically, Theme 2 and its sub-themes showed that adolescents' MEs affected the resolution of majority of MPs, and the inverse was more likely contradictory.

Research Problem 3: What factors from the local context (FLCs) influenced adolescents' ways of settling their moral problems (MPs)? 
Diverse FLCs (e.g., admonishment by classmates, parental treatment, grandmother's religious teaching) helped in the resolution of participants' MPs (e.g., arrogance, physical defect, churchgoing). Additionally, FLCs that helped resolve MPs were similar or dissimilar from one another and yet mostly settled adolescent students' MPs since they saliently and accurately reflected moral choices, decisions, and actions in daily life (FeldmanHall, et al., 2012). Further, FLCs mentioned under particular MPs reemerged within and across MPs and their themes. Briefly stated, Theme 3 and its sub-themes revealed that adolescents' FLCs impacted on the resolution of majority of MPs, and the inverse was more likely untrue.

Research Problem 4: How did adolescents' personal moral beliefs (PMBs) guide them when resolving their moral problems (MPs)?

Personal moral beliefs (e.g., "Learn to listen to others," "Learn to accept other people's deficiencies," "Honesty is the best policy") guided the resolution of participants' MPs (e.g., arrogance, bullying, familial lying). Additionally, PMBs that helped resolve MPs were similar or dissimilar from one another. Further, most PMBs mentioned under particular MPs reemerged within and across MPs and their themes. Most commonly and equally expressed sources of moral beliefs were both the "self" and "school." Succinctly, Theme 4 and its sub-themes revealed that adolescent students' PMBs affected the resolution of majority of MPs, and the opposite was more likely untrue. Further, because adolescents were mostly influenced by their family, school, religion, and community (that is, whether having been taught about various ethical principles), their PMBs were mostly adoption, conformity, assimilation, and acculturation; hence, the use of moral beliefs that they deemed to or appeared to eclectically work for them as they navigate their moral worlds. Reflective of their PMBs, they used "virtue ethics" followed by "personal ethics," which were consistent with the K-12 curricular framework for Values Education of the Philippine Department of Education (Philippine Department of Education, 2012. Nevertheless, with due consideration to the specific finding of this study where other major ethical worldviews were in background operation in the lived moral experiences of the research participants, further research is recommended among DepEd's high school adolescents given the non-primacy or nonmonopoly of any particular ethical/moral philosophies over others (Agustin, 2016).

Research Problem 5: How morally reflective (MR) were adolescents of their personal moral beliefs (PMBs) when resolving moral problems (MPs)?

Moral reflectiveness (MR) revealed the advantages of PMBs in the resolution of participants' MPs. Similarly, participants' MR was evident not only on the advantages and disadvantages of their personal moral beliefs, but also on the challenges they overcame and for they did not set aside their moral beliefs when resolving similar moral problems. Hence, aside from many experts who favored the development of adolescent students' moral reflectiveness for ethical problem resolutions, extra attention and communicative moral reflective exchanges should be afforded among adolescent individuals who break rules and standards using their stated PMBs that run against societal norms. Briefly, respondents who were reflective of the pros and cons of their PMBs more likely resolved their MPs as they tended to have cultivated critical- 
reflective thinking strategies that they might just have often taken for granted (Wielgus, 2015).

Research Problem 6: How morally consistent (MC) were adolescents of their personal moral beliefs (PMBs) when resolving moral problems (MPs)?

Moral consistency (MC) disclosed adolescents' reliability in their use of PMBs for the resolution of MPs, that is, between moral judgment and moral action (Kohlberg \& Kramer, 1969). MC was most evident among participants who resolved their respective MPs. Likewise, participants' MC was more manifested among adolescents who overcame challenges, did not set aside, depended and stood firm on their PMBs in resolving related MPs. Contrariwise, despite the participants' moral conviction favoring the use of resolving PMBs that break societal moral codes, much-needed emphasis is warranted in those few specific deviant or outlier cases (Abraham, Takwin, \& Suleeman, 2018).

Research Problem 7: What are the implications of this study for the advancement of Values, Moral, Ethical Education to the youth?

This phenomenological research did not produce generalizable results. Even so, the following are the implications of the findings of the study: First, adolescent students most likely resolve their moral problems effectively using their personal moral beliefs and related factors that they view to be beneficial for them and to those they affect. Additionally, adolescents decide on the resolution of their moral problems using not just their personal moral beliefs, but also their personal characteristics, moral experiences, and factors from the local context. Second, parents, teachers, and other capable individuals can help adolescents find ways on how to decide on moral problems through constructive dialogue, and critical thinking and acting with integrity. Likewise, parents, teachers, other concerned individuals, and adolescent students themselves must work together ethically to minimize or resolve conflicts among themselves. Finally, yet much more importantly, further studies are essential concerning the aforementioned implications so that adolescent students and other concerned individuals are included in disclosing voluntarily their side about a specific moral problem. In essence, additional researches are needed to explain and evaluate the extent to which, in theory and practice, adolescents use their personal moral beliefs that are most helpful and beneficial not only for them, but also to the larger society. Through a collaborative effort, Moral / Values Education facilitators can improve and evaluate further effective ways to teach the various subject matters using personal autonomy, individual and collective integrity, and collaborative rationality, as well as, sense- and meaning-making.

\section{CONCLUSION}

A variety of PCs, MEs, FLCs, and PMBs, as unified multiple-dimensional influencers, revealed how adolescents were helped in resolving majority of their respective MPs. At the core is a unifying moral belief system where most individual interviewees were reflective and consistent in using their PMBs in association with their PCs, MEs, and FLCs as guides in resolving their MPs. Youth's PMBs were better concretized in relation to their use of PCs and the effects that daily MEs and FCLs have on them 
(Hong, Guo, \& Chen, 2015; Iwasa, 2017; Niemirowski, 2014). In like manner, PMBs were closely knitted to adolescent students' PCs, just like MEs and FLCs. Moreover, at the heart of resolving MPs were the deeply-held PMBs of adolescents; on the contrary, at the heart of not resolving MPs were, in the adolescents' own words, diversionary or unhelpful PMBs, PCs, MEs, and FLCs (Abraham, Takwin, \& Suleeman, 2018). The specific results' implication for education is that PMBs and related factors are significant in the heuristic, self-learning or "hands-on" resolution of MPs, which can be interpreted as the manner in which adolescents consistently reflect on their personal moral circumstances (Kleinman, 1999; Mattingly2012). In other words, the adolescents resolve their MPs, not just with their PMBs, but also by drawing out their moral judgments from a host of associated factors (i.e., PCs, MEs, \& FLCs) (Balakrishnan, 2009; De Leon, 1995; Fried, 1997).

\section{RECOMMENDATIONS}

The significant findings of this original research paper call for future replications and thereby useful submissions from various experts and other concerned parties, as follows:

1. In collaboration, education officials and experts, scholars, researchers, administrators, parents, teachers, and other stakeholders should focus more on collective personal eclectic ethics, related determinants, MR, and $\mathrm{MC}$ in moral resolutions that impact on adolescent students' lives, other areas of a community, and larger spheres of society.

2. Researchers should study in more specific details about PMBs, controlling for other factors, that may or may not run counter to organized inter-subjective moralizing, such as individual PMBs versus societal implicit rules (e.g., academic dishonesty under desperation, computer addiction due to inadequate self-control). Moreover, they should also use mixed methods research methodology or quantitative research technique other than purely qualitative research. They should also include samples from various school types and levels: school types (i.e., private schools); school levels (e.g., pre-elementary, primary, tertiary); other regions of the world; inter alia.

3. Scholars should work together with Ethical / Values / Moral Education teachers', parents', and other authorized concerned parties' PMBs in dealing with adolescents' MPs to derive/arrive at relatively eclectic ethical views of heuristic moral problem resolution amorphous to our ever-evolving world. 


\section{REFERENCES}

Abraham, J., Takwin, B., \& Suleeman, J. (2018). Counterfeit Self: A Confirmatory Factor Analysis among Indonesians, Kasetsart Journal of Social Sciences, 39(3), 518525. https://doi.org/10.1016/j.kjss.2017.07.011

Acido, M. (2004). Philosophical skills of education students at the preservice level. Quezon City: (Unpublished Doctoral Dissertation). University of the Philippines.

Agustin, E. (2016). Arguments for or Against an (emerging) Eclectic Theory of Law, International Comparative Jurisprudence, 2(2), 61-66.

Balakrishnan, V. (2009). Teaching moral education in secondary schools using real-life dilemmas. (Unpublished Doctoral Dissertation). Victoria University of Wellington, New Zealand.

Becker, L., \& Becker, C. (2013). Encyclopedia of Ethics. New York: Routledge.

Camp, E. (2016, February 5). Personal Identity (The Narrative Self). Retrieved from WiPhi: Open Access Philosophy: www.wi-phi.com/video/personal-identity-narrativeself

Christakis, N. (1992). Ethics are Local: Engaging Cross-cultural Variation in the Ethics for Clinical Research., Social Science \& Medicine, 35(9), 1079-91.

Creswell, J., \& Poth, C. N. (2018). Qualitative inquiry and research design: Choosing among five approaches (4th ed.). California: SAGE Publications, Inc.

Das, V. (2012). Chapter 8: Ordinary Ethics. In D. Fassin, A Companion to Moral Anthropology (pp. 133-149). Massachusetts: John Wiley \& Sons, Inc.

De Leon, M. (1995). Influence of family, school and societal values on student values of Marist schools in the Philippines: implications for educational policies and practices on basic education. Quezon City: (Unpublished Doctoral Dissertation). University of the Philippines.

Englander, M. (2012). The Interview: Data Collection in Descriptive Phenomenological Human Scientific Research, Journal of Phenomenological Psychology, 43(2012), 1335 .

Fleming, T. (2004). The Morality of Everyday Life: Rediscovering an Ancient Alternative to the Liberal Education. Missouri : University of Missouri Press.

Foot, P. (1983). Moral Realism and Moral Dilemma, The Journal of Philosophy, 80(7), 379-398.

Freakley, M., \& Burgh, G. (1998). Improving teacher education students' ethical thinking using the community of inquiry approach., Analytic Teaching, 19(1). 
Fried, J. (1997). Changing ethical frameworks for a multicultural world. In J. Fried, Ethics for today's campus: New perspectives on education, student development, and institutional management (pp. 5-22). San Francisco: Jossey-Bass.

FeldmanHall, O., Mobbs, D., Evans, D., Hiscox, L., Navrady, L., \& Dalgleish, T. (2012). What We Say and What We Do: The Relationship between Real and Hypothetical Moral Choices, Cognition, 123(3), 434-41.

Giorgi, A. (1988). Validity and reliability from a phenomenological perspective. In W. Baker, L. Mos, H. Rappard, \& H. Stam (Eds.), Recent trends in theoretical psychology (pp. 167-176). New York: Springer-Verlag.

Heidegger, M., Macquarrie, J., \& Robinson, E. (2005). Being and time. Oxford: Blackwell.

Hong, R.-M., Guo, S.-E., \& Chen, M.-Y. (2015). The Experiences of Tobacco Use among South-Western Taiwanese Adolescent Males, International Journal of Environmental Research and Public Health, 12(9), 10522-10535.

Husserl, E. (1900/1970). Logical Investigations (Vol. 1). (J. Findlay, Trans.) New York: Humanities Press.

Iwasa, N. (2017). Children's Everyday Experience as a Focus of Moral Education, Journal of Moral Education, 46(1), 58-68.

Kleinman, A. (1999). Moral Experience and Ethical Reflection: Can Ethnography Reconcile Them? A Quandary for "The New Bioethics", Bioethics and Beyond, 128(4), 69-97.

Kohlberg, L. and Kramer, R. (1969). Continuities and Discontinuities in Childhood and Adulthood Moral Development, Human Development, 12, 93-120.

Küpers, M. (2009). The Status and Relevance of Phenomenology for Integral Research, Integral Review, 5(1), 51-95.

Magsino, M. C. (2013). A Phenomenological Inquiry on the Human Person: A Realist Personalist Philosophy of Education. Quezon City: (Unpublished Thesis: University of the Philippines).

Mattingly, C. (2012). Moral Selves and Moral Scenes: Narrative Experiments in Everyday Life, Ethnos: Journal of Anthropology, 6, 301-327.

McAleer, G. (2006). The Conservative Moral Philosophy of Scheler and Kolnai. Modern Age, 217-225.

Merleau-Ponty, M. (1945/2013). The Phenomenology of Perception (1st ed.). (D. Landes, Trans.) London: Routledge.

Merriam, S. (2007). Qualitative research and case study applications in education: Revised and Expanded from Case Study Research in Education (2 ${ }^{\text {nd }}$ ed.). California: Jossey-Bass. 
Moody-Adams, M. (1997). Fieldwork in Familiar Places: Morality, Culture and Philosophy. Massachusetts: Harvard University Press.

Moustakas, C. (1994). Phenomenological research methods. California: Sage Publications.

Niemirowski, T. (2014). Two aspects of identity as determinants of human moral development, Horyzonty Psychologii, 7-44.

Philippine Department of Education (DepEd). (2012, January 31). Gabay sa Kurikulum ng K to 12 Edukasyon sa Pagpapakatao: Unang Baitang at Ika-7 Baitang (Curriculum Guide of $K$ to 12 Values Education: Grade 1 and Grade 7.

Riley, S. (2013). Building a High School Philosophy Program, Teaching Philosophy, 36(3), 239-252.

Rocca, d. (2014, August 29). Locke on Personal Identity. Retrieved from WiPhi: Open Access Philosophy: www.wi-phi.com/search/node/locke

Santiago, H. J. (2012). Ethical frameworks and Values Education in Bulacan Public National High Schools. Quezon City: (Unpublished doctoral dissertation). University of the Philippines.

Schroeder, N. (2008). Moral Dilemmas in Contemporary Virtue Ethics. California: (Unpublished Master's Thesis). University of New Orleans. Retrieved from http://etd.1su.edu/docs/available/etd-04182011-213419/unrestricted/SchroederThesis.pdf

SEAMEO-INNOTECH. (2012). K TO 12 TOOLKIT: Reference Guide for Teacher Educators, School Administrators and Teachers. Retrieved from Southeast Asian Minister of Education, Organization, Innovation and Technology: http://www.gov.ph/downloads/2012/201209-K-to-12-Toolkit.pdf

Shoemaker, D. (2015, December 15). Personal Identity and Ethics. Retrieved from Stanford Encyclopedia of Philosophy: http://plato.stanford.edu/entries/identity-ethics/

Smith, J., \& Osborn, M. (2015). Interpretative phenomenological analysis as a useful methodology for research on the lived experience of pain. British Journal of Pain, 4142 .

Stichter, M. (2018). The Skillfulness of Virtue: Improving our Moral and Epistemic Lives. New York: Cambridge University Press.

UNESCO. (2002). Learning to be: A holistic and integrated approach to values education for human development: Core values and the valuing process for developing innovative practices for values education toward international understanding and a culture of peace. Sourcebook No. 2. Bangkok: UNESCO, UNESCO-APNIEVE.

van Manen, M. (1990). Researching lived experience: Human science for an action sensitive pedagogy. Albany: State University of New York Press. 
Wagner, L., \& Ruch, W. (2015). Good Character at School: Positive Classroom Behavior Mediates the Link between Character Strengths and School Achievement, Frontiers in Psychology, 6, 610.

Wielgus, M. D. (2015). Critical-Reflective Thinking: A Phenomenology. Retrieved from http://search.ebscohost.com/login.aspx?direct=true $\& d b=d d u \& A N=3261 B 45 A B 1 D 70 D$ DE\&site=ehost-live

Zhang, Y and Chen, M (2018). Character Strengths, Strengths Use, Future SelfContinuity and Subjective Well-Being Among Chinese University Students. Front. Psychol. 9, 1040.

Zigon, J., \& Throop, C. (2014). Moral Experience: Introduction. ETHOS, 42(1), 1-15. 